\title{
Gingando na Lusofonia: A institucionalização da capoeira em Portugal
}

\author{
Ricardo Carvalho ${ }^{1}$
}

\begin{abstract}
Resumo
A capoeira é uma prática cultural e esportiva de origem afro-brasileira que chega a Portugal no final dos anos oitenta com a emigração brasileira e hoje é praticada em todo país. O presente artigo pretende analisar o impacto decorrente do processo de institucionalização da capoeira em Portugal, iniciado pelo Estado português em 2010, junto à comunidade luso-brasileira de praticantes. Tenciona ainda: verificar as contradições do processo no que toca à compreensão dos diversos atores sobre $o$ que é a capoeira e como deve ser concebida, bem como perceber as relações de poder entre o Estado e as instituições desportivas representativas dos capoeiristas. A fim de realizar esta tarefa, foram entrevistados os diferentes atores envolvidos e analisada a documentação referente ao tema.
\end{abstract}

Palavras-chave: Capoeira. Esporte. Cultura. Institucionalização.

\section{DANCIN' WITHIN LUSOPHONY: CAPOEIRA'S institutionalization in Portugal}

\begin{abstract}
Capoeira is a cultural and sports activity of african-Brazilian origin that arrived in Portugal in the late eighties with the Brazilian emigration and which is practiced today throughout the country. This article aims to analyze the impact of the capoeira institutionalization process in Portugal, initiated by the Portuguese state in 2010 together with the Luso-Brazilian community of practitioners. It intends to: (a) verify the contradictions of the process regarding the understanding of the various actors about what capoeira is and how it should be conceived, as well as (b) identify power

1 Professor-Doutor do Instituto de Humanidades e Letras da Universidade da Integração Internacional e da Lusofonia Afro-brasileira (UNILAB), Brasil. ricardonascimento@unilab.edu.br
\end{abstract}


relations between the state and representative sports institutions of capoeiristas. In order to accomplish this task, we interviewed the different actors involved and analyzed specific documentation on the subject.

Keywords: Capoeira. Sports. Culture. Institutionalization.

\section{INTRODUÇão}

A prática esportiva, regrada, sempre foi alvo de atenção do Estado desde os tempos da sua tenra concepção como conduta representativa de um possível adestramento físico e social do cidadão. A própria codificação de diversas atividades desportivas ocorreu, por várias razões e em muitos casos, em concomitância com a formação dos estados-nações. Em parte, por terem sido pensadas como práticas de "refinamento" e construção do corpo do cidadão nacional e, em algumas ocasiões, como elemento que representa simbolicamente a nação, caso particular da capoeira e de inúmeras Artes Marciais². Os métodos ginásticos aplicados no Brasil, durante a primeira parte do século $X X$, tinham as mesmas funções dos seus países de origem: disciplinar os corpos e formar cidadãos saudáveis, robustos e disciplinados para a vida em sociedade, o que Falcão (1996) conceituou como Educação Física Higienista.

Dialogando com Elias (1992), é possível afirmar que a constituição do desporto moderno fez-se a partir de rupturas que, por sua vez, foram realizadas em vários domínios sociais. Entre estas rupturas, por exemplo, está um processo de secularização como expressão de um desligamento de um campo religioso ao qual as Artes Marciais estavam atreladas, a criação de espaços próprios de ação esportiva, o estabelecimento de uma temporalidade específica e regrada para o esporte, a codificação de regras e normas, bem como a adoção de estandardizações que permitem qualquer desporto tornarse universal. E é a partir desta análise de Elias que nos perguntamos

2 Entenda se Artes Marciais como práticas de destreza corporal associadas aos esportes de combate, luta e defesa pessoal. 
em que medida tais proposições continuam ainda em andamento e são reinventadas para formatar práticas sociais e culturais que pretendem ser reguladas pelo Estado, tendo em conta um tipo de formatação da sociedade como um todo. A partir desta reflexão teórica, traçamos como objetivo central tentar compreender de que forma o Estado português relacionou-se com a capoeira e seus praticantes, no território nacional, de maneira a aplicar a lei e fazer valer uma visão social interpretativa própria sobre as práticas que concernem ao esporte, categoria onde inseriu a capoeira. Para além disso, o artigo pretende compreender os meandros do processo de institucionalização da capoeira, tendo em conta as relações entre o Estado e os diferentes agentes sociais, neste caso os capoeiristas, e entre os diferentes agentes entre si, na formatação e concepção de como cada um deles, percebe, interpreta e projeta a capoeira a partir de Portugal. Do ponto de vista metodológico, a pesquisa inseriu-se num processo de observação participante que incidiu no acompanhamento das reuniões realizadas pelo Estado, entre os capoeiristas, nos diálogos informais, em entrevistas, na participação e acompanhamento de fundação das Federações de capoeira locais e análise dos documentos oficiais. A condição de nativo e praticante de capoeira do pesquisador permitiu seguir a temática de perto por quase uma década, sendo possível realizar o seu registro sistemático nos anos de 2010 a 2014.

No caso concreto da capoeira em Portugal, o paradoxo reside em tratar-se de uma prática de cultura, e também esportiva, cujas origens mantêm relações com o colonialismo português, o tráfico de escravizados para o Brasil e a formação de culturas crioulas decorrentes desse revés da história do colonialismo. Hoje, em Portugal - praticada por portugueses, luso-africanos e brasileiros emigrados -, a capoeira tende a ser apropriada, por estes atores sociais, como uma prática lusófona, designação genérica e imprecisa que abarca as culturas de língua portuguesa do atlântico negro, mas que em Portugal está 
fortemente carregada pelo lusocentrismo e relacionada aos "mitos da democracia racial". No entanto, para o Estado português, a capoeira é, unicamente, uma prática esportiva como qualquer outra, sendo desvalorizada sua presença atual em território nacional, bem como invisibilizados seus aspectos culturais e históricos que - direta e indiretamente - guardam estreitas relações com o colonialismo português enquanto possibilidade de conformação da prática.

É no final do século XIX que grande parte das Artes Marciais verão seus códigos sistematizados. Segundo Assunção (2014), os desportos de combate orientais se desenvolveram entre 1850 e 1950. Em 1882, Jigoro Kano, criador do Judô, abriu em Tóquio a sua primeira academia e introduziu uma série de inovações como o uso do uniforme, o sistema de faixas e minimizou a marcialidade do combate dando ênfase na prática física e desportiva. Este processo culminou com a internacionalização do Judô e, posteriormente, do Jiu Jitsu a partir da diáspora nipónica no início do século XX.

Sabe-se que, no caso brasileiro, a institucionalização da capoeira se inicia nos anos trinta, durante o governo nacionalista de Getúlio Vargas com os mestres Pastinha e Bimba que, respectivamente, criaram dois segmentos importantes da capoeira, denominados de Regional e a Angola. Numa breve consulta nos motores de busca, na internet, facilmente se pode encontrar a foto mítica que marca o momento histórico em que Bimba, o famoso mestre baiano, aperta mãos com o então presidente Getúlio Vargas, ainda nos anos trinta do século $X X$, momento em que o estadista revela ter encontrado o verdadeiro esporte nacional: a capoeira. Foi este encontro providencial que possibilitou a legalização das primeiras academias onde se podia treinar a capoeira. Será importante assinalar que, entre os finais do século XIX e início do século XX, o capoeirista, enquanto tipo social negro, pobre e marginalizado, era associado à criminalidade, aos desacatos a ordem pública, brigas e à anomia social. Segundo Soares 
(1994), em 1890 a capoeira encontrava-se penalizada no Código Penal brasileiro com duras penas aos seus praticantes, fato que só obteve mudança no século seguinte. Para Vieira (1995), a posterior retirada da capoeira do Código Penal, sua institucionalização em academias e sua aceitação pelo Estado compreenderiam uma estratégia de cooptação pelo Estado nacionalista para representar a identidade nacional brasileira, juntando-se a outras práticas culturais e religiosas como o samba e as religiões de matriz africana no Brasil.

Em Portugal, a capoeira chega nos anos oitenta com a emigração brasileira em direção aos países industrializados e na sequência da crise econômica no Brasil. No início dos anos noventa foram criadas, em território Luso, as primeiras associações de praticantes, organizados os primeiros encontros e fixaram-se os primeiros grupos. Passadas algumas décadas, a capoeira faz parte da paisagem humana local e é comum ver os portugueses, bem como os imigrantes de países africanos lusófonos, adotarem a capoeira como profissão e estilo de vida.

Depois de um longo período de informalidade, a capoeira passou por uma fase de crescimento que demandou a criação de instituições como associações juvenis, desportivas ou culturais, a fim de obter reconhecimento frente ao Estado português, angariar recursos e credibilidade junto à sociedade local. A obtenção de licenças para abertura de espaços de treino, apresentações públicas, realização de eventos e realização de performances pagas teve de preceder à criação de associações que permitissem a existência institucional dos capoeiristas, mas também à realização de uma série de outros procedimentos como passar recibos e abrigá-los institucionalmente em locais socialmente credíveis; necessidades que antes inexistiam, mas que decorreram do crescimento natural da arte e da busca de novos espaços de ação. Para os capoeiristas brasileiros, a abertura de associações de praticantes significou uma existência social, a possibilidade de diálogo vertical 
com outros setores da sociedade e, em alguns casos, uma possibilidade de obter um visto de trabalho e a posterior legalização.

A partir de 2009, as instituições do Estado português passaram a exigir de todos os profissionais de áreas esportivas, sem formação superior em Educação Física, que obtivessem uma "cédula profissional" a fim de que pudessem continuar a exercer a sua atividade. A cédula tinha a duração de 05 anos e poderia ser obtida através de modalidades que tivessem federações, bem como junto ao IPDJ (Instituto Português do Desporto e Juventude). A obtenção de tal cédula passava inicialmente por uma fase de pagamento e envio de documentos, via correio eletrônico, que comprovasse a idoneidade do praticante e desse conta da sua biografia enquanto profissional da modalidade. Entre estes documentos podiam constar recortes de jornais, fotografias, diplomas, certificados e cópias de documento de contratação, enfim, tudo que pudesse provar que a pessoa em causa era de fato um profissional atuante.

Contudo, regulamentações posteriores do IPDJ e o fim do período de renovação da cédula, levaram a criação de Federações que, por sua vez, encarregaram-se de "certificar" os capoeiristas, bem como de executar planos de qualificação profissional dos mesmos. É importante esclarecer que, por comunidade de praticantes de capoeira em Portugal, tomamos os brasileiros que introduziram a modalidade nos anos oitenta e os demais que chegaram durante os anos noventa e nas décadas seguintes com o intuito de ensinar a capoeira, assim como os praticantes portugueses e da África lusófona residentes em Portugal. Também será importante referir, para que se compreenda o processo de transnacionalização da capoeira em Portugal e na Europa, que os brasileiros sempre fizeram parte de uma elite de "especialistas nativos" cujo domínio e legitimidade da arte serviu como instrumento de validação nas relações de poder com os locais. Esta "legitimidade orgânica" acabou por figurar-se como elemento de embate e tensão 
nas disputas entre os diversos setores que participaram do processo de profissionalização e institucionalização da capoeira.

$\mathrm{O}$ presente artigo pretende analisar as contradições deste processo, tendo em conta as relações entre as lideranças dos grupos de capoeira, as disputas de legitimidade e poder junto à comunidade de praticantes e a visão dos diferentes órgãos estatais de intervenção no tema.

\section{A Institucionalização e Profissionalização da Capoeira no Brasil}

A ideia da capoeira como esportenãoénova, eo seu atrelamento a esta semântica tem caminhado ao lado da ideia de institucionalização e profissionalização da sua prática corriqueira. Contudo, posicionála apenas como prática esportiva seria despi-la de sua roupagem identitária original, de sua afro-descendência. Seria, também, dotá-la de regras, normas, precisões que ela não possuía nem lhe interessava como mote de vadiação ${ }^{3}$ dos antigos negros escravizados. Autores como Mello Moraes, Coelho Neto, Aníbal Burlamaqui e Inezil Penna Marinho foram, ao longo do século $X X$, defensores de uma proposta acética para a capoeira, imaginando-a como um desporto, de combate sobretudo, desprovido de elementos da cultura negra se possível, com regras estritas, uma espécie de "ginástica nacional". Em 1907, um oficial anónimo das forças armadas brasileiras publicaria o livro $O$ guia da Capoeira ou ginástica Brasileira. Em 1928, Coelho Neto, no artigo "Nosso Jogo", defenderia a possibilidade de inclusão da capoeira nas escolas civis e militares e, ainda, em 1928, Aníbal Burlamaqui (1928) publicaria o livro Ginástica nacional (capoeiragem), metodizada e regrada.

Esta proposta de uma capoeira inteiramente "embranquecida", nacional e desportiva, muito aliciante por sinal para alguns, nunca

3 Vadeação era um dos nomes dados a prática habitual da capoeira nos locais públicos para fins lúdicos. 
chegou a vingar e a constituir-se plenamente como opção, embora desdobramentos desse viés façam sucesso ainda hoje junto às Federações e a grandes grupos que promovem campeonatos e torneios de luta, entre outras formas de competições. No entanto, conforme Falcão (1996), durante o regime militar no Brasil, a partir de 1964, ocorreu uma política de apadrinhamento nacionalista da capoeira que culminou com o seu atrelamento à CBP (Confederação Brasileira de Pugilismo) e, em 1ํ de Janeiro de 1973, passou a vigorar o Regulamento da Capoeira, editado pelo Departamento de Capoeira da CBP. Posteriormente foram criadas as Federações estaduais de capoeira, tais como a Federação Paulista e Carioca de Capoeira. Neste período foram ainda criadas graduações com as cores da bandeira brasileira, ainda em voga em muitos grupos.

Nos anos noventa foi promulgada no Brasil a Lei de número 9.696/98, que tinha por finalidade ordenar a profissão de educador físico e que cria o CONFEF (Conselho Federal de Educação Física) e os CREF (Conselhos Regionais de Educação Física). A partir desta Lei, seguiram-se ações internas de regulamentação da profissão que, de alguma forma, tocavam outros profissionais sem formação acadêmica na área, porém detentores de saberes particulares no âmbito desportivo das suas práticas. Segundo Fonseca (2010), tratavase de uma ação corporativista que visava a resguardar nichos de mercado para o segmento da Educação Física, antes ocupados por profissionais específicos, caso dos mestres de capoeira, dos mestres das Artes Marciais orientais, professores de Yoga, entre outros. Conforme a autora, tentava-se forçar os capoeiristas a obterem o curso de Educação Física ou inscreverem-se junto aos Conselhos Regionais para que retirassem, mediante um curso específico, os respectivos documentos a fim de que pudessem lecionar a capoeira.

O que estava em causa na citada Lei era uma forma de regulação estatal sobre a capoeira e os seus saberes, desconsiderando 
aspectos do ensino da arte, sua ligação com a cultura afro-descendente no Brasil e, acima de tudo, com o saber popular dos mestres que teriam de aderir ao "sistema meritocrático" dos conselhos para se habilitarem enquanto profissionais. Em verdade, a ofensiva do Estado encontrou resistência e, conforme Fonseca (2010), formou-se no ano 2000, entre os descontentes com as novas regras, a Frente Unida pela Autonomia Profissional da Educação e das Tradições Populares, um movimento que congregava capoeiristas, profissionais das Artes Marciais, professores de dança e Yoga.

É importante salientar que alguns segmentos, como a Capoeira Angola, mantiveram-se à parte deste movimento por considerar que sendo um património cultural, oriundo dos africanos escravizados no Brasil, não poderiam ser tratados como desporto e, como tal, seus praticantes posicionaram-se à margem de qualquer movimentação institucional. No entanto, em 2008 é aprovado o projeto de Lei 7.150/02 que reconhece a prática da capoeira como profissão e suprime a exigência de inscrição da capoeira nos Conselhos. Esta medida surge no seguimento do reconhecimento da capoeira pelo governo brasileiro como sendo parte do Patrimônio Imaterial Nacional no ano de 2008, em processo levado adiante pelo IPHAN.

\section{A Capoeira em Portugal}

Foi por volta da década de setenta que a capoeira começou a ser formalmente ensinada fora do Brasil. Participaram deste processo figuras de destaque no mundo da capoeiragem como os mestres Jelon Vieira e Bira de Almeida (mestre Acordeon) nos Estados Unidos, bem como os mestres Nestor Capoeira e Martinho Fiúza na Europa. Nestes tempos idos de desbravamento de novos nichos de mercado, não se avistava a perspectiva de que, um dia, a capoeira seria ensinada, produzida e difundida pelos habitantes locais nascidos nos países 
onde a prática se estabeleceu e, mais ainda, formaria comunidades de praticantes nacionais gestoras, em cada país, do andamento da difusão da arte.

Os relatos dos primeiros praticantes indicam que, inicialmente, uma vez que se desconhecia a capoeira, a informalidade, a liberdade de açãono ensino, permitiu que qualquer um, mesmo sendo um emigrante indocumentado, pudesse ensinar, uma vez que a proficiência da arte baseava-se no critério implícito de que o profissional a lecionar era um brasileiro com uma vivência íntima com a prática da capoeira.

Tendo sido implantada por força da crescente imigração brasileira que se fez sentir sobretudo na década de noventa, o processo de transnacionalização da capoeira em território nacional beneficiouse de um conjunto de fatores de ordem social, política, económica e cultural das décadas posteriores ao 25 de Abril de 1974. O fim do extenso período colonial, a redemocratização do país, o incremento demográfico decorrente da vinda dos "retornados" e a passagem de um país emissor de migrantes para um espaço receptor, assim como a adesão à União Europeia e à moeda única, tornaram Portugal um país aparentemente atraente, moderno, culturalmente diverso e tolerante. Eventos como a Expo 98, a comemoração dos 500 anos dos Descobrimentos, a constituição da CPLP (Comunidade dos Países de Língua Portuguesa) ajudaram também a reconstruir, num contexto pós-colonial, a esfera espacial da língua portuguesa com a marca do que hoje se convencionou chamar de Lusofonia. Assim, a década de noventa foi bastante prodigiosa para a expansão da prática da capoeira em Portugal com um aumento significativo de grupos e do número de praticantes. Nos finais da década de noventa, começaram a surgir os principais encontros de capoeira que ganharam uma marca internacionalizada como o "Nosso Encontro", realizado em Évora e o "Meeting de Capoeira", que tem lugar na cidade de Faro. 
Ainda na década de 70, iniciavam-se em Portugal, conforme Pordeus Junior (2009) e Saraiva (2011), as práticas religiosas afrobrasileiras introduzidas por emigrantes portugueses que se tinham integrado nesses cultos religiosos no Brasil. Ainda que a capoeira não tenha entrado em território nacional a partir do retorno de emigrantes nacionais vindos do Brasil, o seu início e rápida difusão deram-se pela abertura proporcionada pelas mudanças na sociedade portuguesa ocorridas nas décadas de 70 e 80 que proporcionaram, por sua vez, a adesão a outras práticas de origem afro-brasileira, como foi o caso do Candomblé e da Umbanda acima referidos. Cabe salientar o papel dos media e da literatura na formação de um imaginário da cultura dos trópicos, mas também de influência nos hábitos sociais dos portugueses, nomeadamente a difusão de telenovelas como Gabriela Cravo e Canela e Sinhá Moça ${ }^{4}$ e os livros Capitães de Areia e Tenda dos Milagres, de Jorge Amado. Era veiculada uma tropicalidade exótica, despida de preconceitos e uma cultura alegre e etnicamente "bem resolvida". Por isso, quando da introdução da capoeira, mesmo com o seu desconhecimento, ela foi acolhida com facilidade numa sociedade sedenta por experimentar outras formas de pertença.

Destaco, no caso português, a importância da imigração brasileira como marco inicial da capoeira em território luso, como parece ser o padrão de crescimento em quase toda a Europa. Todo o contexto enumerado, designadamente a entrada na União Europeia, a adesão ao Euro, a Expo 98 e a Comemoração dos Descobrimentos colaboraram para Portugal se tornar um destino de interesse ao imigrante brasileiro. Conforme o estudo realizado por Carlos Vianna, em 2002, quando ocupava o cargo de Presidente da Casa do Brasil em Lisboa, existe um conjunto de fatores específicos que explicam a escolha dos imigrantes brasileiros por Portugal:

4 A telenovela Gabriela Cravo e Canela foi lançada em 1985 pela TV Globo e Sinhá Moça em 1986 pela mesma emissora. 
- "A facilidade da língua comum e da cultura mais próxima, aliada à existência de alguns acordos bilaterais;

- A procura de profissionais brasileiros ou a conquista de "nichos" de mercado de trabalho ou de serviços por parte de alguns setores profissionais específicos (dentistas, informáticos, publicitários e, nos últimos anos, trabalhadores da restauração, comércio e hotelaria), que tende a gerar um efeito de auto-alimentação das vagas e oportunidades de trabalho;

- A possibilidade da obtenção de nacionalidade portuguesa por laços de parentesco e o retorno de um certo número de emigrantes portugueses do Brasil, a partir do início dos anos 90, com as suas famílias brasileiras;

- Os significativos investimentos econômicos de empresas brasileiras em Portugal, nomeadamente nos primeiros anos da década de 90 e, nos últimos 5 anos, de empresas portuguesas no Brasil;

- A ideia, parcialmente incorreta e ilusória, de que Portugal seria uma espécie de "porta de entrada" para a Europa ou passagem para os Estados Unidos e que ofereceria maiores "facilidades" para os brasileiros (VIANNA, 2002, p. 2-3).

Formalmente a história da capoeira em Portugal começa com Afránio Gouveia Silveira, o Mestre Magôo. Este iniciou a sua formação com Mestre Ivan, em 1975, no Estado de Minas Gerais, tendo mais tarde mudado para o Estado do Rio de Janeiro, onde fundou a associação da qual é líder:

“Cheguei em Portugal no dia 19 de Setembro de 1987, e logo no mês seguinte (Outubro) já ministrava aulas de capoeira numa sala na rua de Santa Catarina, próximo ao Marquês de Pombal, no Porto." (Depoimento de Mestre Magôo, 2010).

Segundo Nascimento (2015), no ano de 1991 registrava-se, legalmente no Registo Comercial de Lisboa, a Associação de Capoeira Negro Nagô de Angola, a primeira instituição vocacionada para a 
capoeira em Portugal. Mestre Umoi, também um dos pioneiros na capoeira em território luso, chegou a Portugal em 1990, tendo trabalhado inicialmente numa rádio. $\mathrm{O}$ mestre enfatiza que "a maior dificuldade inicial era que ninguém sabia o que era capoeira, pensava que era galinha". Após procurar vários ginásios e ver negado o seu pedido para ensinar a capoeira, o mestre resolveu pôr no jornal uma notícia: "quem era capoeira e se tivesse algum outro capoeirista que o procurasse". Sem opções, acabou por iniciar na rua o ensino da arte e, no dia 11 de setembro de 1990, deu a sua primeira aula de capoeira em Portugal. Nascia ali, então, o grupo União na Capoeira em Portugal.

No ano de 2003, um levantamento realizado por Falcão (2004) contabilizava que existiam cerca de 35 professores brasileiros a dar aulas em Portugal, entre mestres, contramestres e instrutores. Segundo tal estudo, a maioria destes profissionais é proveniente da região Nordeste do Brasil, em especial das cidades do Recife e Salvador. Por volta de 2010, no levantamento que realizei junto aos grupos, considerando seus líderes e alunos, foram contabilizados cerca de 55 grupos espalhados por todo o território nacional. Destes, 13 grupos foram criados "de raíz" em Portugal e refletem um crescimento endógeno do fenómeno da capoeira. Quanto ao número de profissionais a ministrar aulas, estimo que durante aquele ano se aproximava dos 100. Entre estes 100, julgo que uma parte significativa seja de portugueses, provavelmente a maioria, resultado de um trabalho que já dura, desde o seu início, mais de duas décadas em Portugal. É de salientar o crescimento da Capoeira Angola, com cerca de quatro grupos a atuar em Portugal, em particular nas cidades de Lisboa e Porto. Realço que o crescimento destes grupos não se faz notar nem tanto no âmbito quantitativo do número de praticantes, mas sim na forma como influenciam a restante da comunidade na organização de rodas, eventos e no tratamento dado à capoeira (NASCIMENTO, 2015). 


\section{A institucionalização da capoeira em Portugal: CONTORNOS E CONTROVÉRSIAS}

O contexto social, político e econômico europeu passou por grandes transformações nos últimos anos, em particular, no caso dos países pertencentes à União Europeia, cuja regulação política e econômica depende de instituições supranacionais como o Parlamento Europeu e a Comissão Europeia, entre outros. As regulamentações no âmbito desportivo europeu, disponíveis nos sítios da internet da Comissão Europeia, expressam preocupações com o crescimento no setor do desporto em toda UE (União Europeia). A página destaca o vigoroso crescimento econômico da área do desporto, o aumento do emprego no setor e a relação com outras áreas como a publicidade televisiva, o cinema, o entretenimento, o turismo e o lazer. Segundo as referências da Comissão Europeia (UNIÃO EUROPEIA, 2016), o setor do desporto emprega cerca de quinze milhões de pessoas, o que representa $5,4 \%$ de toda força de trabalho da UE. Conforme ainda a mesma fonte, tem-se verificado um aumento significativo de casos judiciais em volta do desporto, o que eles interpretam como sendo resultante das disputas de mercado no setor dentro da União Europeia. Esta breve introdução nos permite perceber que, de uma área pouco relevante, o desporto tornou-se um negócio lucrativo e em expansão que merece a atenção do Estado e dos seus intervenientes.

Tal como foi descrito anteriormente, as cédulas de certificação foram adotadas no ano de 2009 e estavam isentos de obtê-las os profissionais de Educação Física, tendo em conta o conhecimento obtido no seu percurso académico. Contudo, todos os profissionais, licenciados ou não em Educação Física, deveriam realizar um certo número de formações certificadas a fim de garantir a renovação da mesma. 
No caso da capoeira, a necessidade de certificação, que não teria sido posta anteriormente, tomou de surpresa muitos capoeiristas brasileiros que tinham passado, no Brasil, processos dolorosos de certificação junto ao CREF. Ocorre que, no mesmo período, surgia, à margem da comunidade de praticantes, a Federação Portuguesa de Capoeira, primeira instituição criada por locais particularmente vocacionada para dialogar com o estado e tornar-se seu interlocutor junto à comunidade. Um dos mentores e atual presidente é Nelson Barros, jovem de origem cabo verdiana, conhecido como mestre Corisco, que teria sido aluno de um dos pioneiros do Grupo Muzenza em Portugal, o mestre Abdula. O mestre confidenciou-me que o seu antigo aluno não teria passado muito tempo em suas classes, logo considerando-se autônomo na capoeira e reaparecendo mestre e fundador da Federação Portuguesa de Capoeira uns anos depois. À parte das polêmicas de legitimidade, o nosso protagonista manteve-se sempre a ensinar a capoeira em locais públicos da capital portuguesa e quase nunca era visto em rodas e atividades coletivas da capoeira onde podia fazer valer o seu estatuto de líder local de um grupo. Em seus depoimentos, Mestre Corisco confidenciou que o processo de criação da FPC foi moroso, passou por vários entraves legais e, como pude constatar, a sua legitimidade junto aos praticantes não se fez plena. Para que pudesse ser efetivada, a Federação necessitaria do aval dos grupos e de realizar filiações que, só correram, não no âmbito dos grupos, mas pela adesão de núcleos e associações do seu próprio grupo de trabalho que se juntaram para criar a instituição. Em seus relatos, Corisco explicou que, a possibilidade de representar a comunidade de capoeiristas em Portugal decorreu de um longo processo de negociação com o estado desde finais dos anos noventa até muito recentemente, quando o estado necessitou levar adiante as políticas públicas que tencionava nas diversas áreas do desporto. Segundo ele, devido às mudanças de governo, as negociações tiveram de ser 
refeitas até que pudessem ser efetivadas. A formalização da parceria entre o estado e a Federação ocorreu em 2014, mediante apresentação de uma documentação em que eram apresentadas, por parte da FPC, os referenciais teóricos para a realização do curso de formação dos capoeiristas. Nelson Barros confidenciou que os referenciais de criação do curso, tomaram como base as áreas do esporte, saúde, psicologia do esporte e educação física, negligenciando saberes populares, idiossincrasias da formação dos capoeiristas, noções de musicalidade, História e cultura afro-brasileira.

Passado o período transitório, o Estado português, através do IPDJ, tomou a já então criada Federação Portuguesa de Capoeira (FPC) (2015) como interlocutora entre o Estado e a comunidade capoeirística a fim de que a instituição pudesse mediar a implantação do novo Programa Nacional de Formação de Treinadores (PNFT). Tratava-se de nova medida institucional que visava a certificar os praticantes de várias modalidades através de uma formação fornecida por Federações e ou instituições formadoras privadas. O programa estabelece dois níveis de treinadores e, para cada profissional, um tipo de formação específica. Será importante esclarecer que, no entendimento do Estado, uma comunidade de praticantes de capoeira é uma comunidade de atletas e, os seus respectivos líderes, treinadores. $\mathrm{Na}$ sua grande maioria, os praticantes tinham conhecimento da existência da FPC, no entanto, a sua baixa popularidade e ilegitimidade não lhe conferia força que incomodasse a maioria dos intervenientes no processo. O mesmo não pensava o Estado, uma vez que, diante do processo, a Federação teria sido a única a apresentar-se para o diálogo interinstitucional e, como tal, legítima, uma vez que apresentava a documentação necessária, cumprindo as regras estabelecidas. Foram as atribuições delegadas pelo Estado e os poderes de interlocução e implementação da lei que conferiram à Federação a força de diálogo e intervenção de que não dispunha pelas vias habituais, o 
que não deixou de causar desconfortos e tensões. Recordamos que a comunidade "portuguesa" de praticantes é muito heterogênea na sua composição, formada por uma geração de mestres brasileiros, jovens luso-africanos e portugueses. Os diálogos entre estes segmentos sempre foram marcados por tensões que, ademais, andavam à volta de questões de poder, legitimidade e ocupação dos nichos de mercado de trabalho. As interlocuções no interior desses segmentos sempre seguiram lógicas pouco perceptíveis em que um grupo podia ou não apresentar-se como legítimo, a depender das alianças e proximidades que fazia, quase sempre, neste caso a um mestre brasileiro. Contudo, no que toca à Federação, a fraca representatividade da mesma não lhe conferia nem voz nem autoridade, dado que a obrigatoriedade do processo de legitimação estatal se impunha à força e à revelia, não por conquista, interlocução, diálogo e representatividade comunitária.

Para muitos dos profissionais da capoeira o processo era ilícito e tomava de assalto o desenvolvimento da capoeira em Portugal feito até então. Mais ainda, desprezava a importância dos mestres, em particular dos pioneiros do ensino em Portugal, e tratava-se de uma medida meramente economicista, uma vez que as formações podiam chegar a valores elevados e ser realizadas por empresas privadas, como se constatou em outras modalidades, tendo como finalidade o lucro. O preço dos cursos variava muito e podia pender entre os 50 euros e os 600. Esta variação devia-se ao fato da FPC fazer uma concessão da realização dos cursos a alguns mestres e grupos, onde a Federação tencionava barganhar simpatia e proximidade. Diante da sua clientela, o mestre ou líder do grupo poderia contratar os profissionais que desejasse, alguns deles dentro do próprio grupo, praticar o preço que lhe fosse conveniente, auferindo algum lucro e partilhando parte deste com a FPC e o Estado. De uma maneira geral, é possível afirmar que foi um conjunto de elementos que concederam força de legitimidade à Federação, sendo eles: a obrigatoriedade do processo que encurralou os grupos a realizarem o curso, os poderes 
conferidos à FPC pelo Estado, como também, o uso desses poderes, barganhas e pequenas negociações na lida com os grupos.

Em 21 de julho de 2014, o IPDJ realizou uma reunião de esclarecimento que contou com cerca de 50 grupos de capoeira, com seus respectivos líderes, muitos deles brasileiros vindos de várias partes de Portugal. Consta que a referida Federação, FNC, e seu líder não estiveram presentes, segundo alguns, a temer represálias. Nesta reunião, a maioria dos participantes contestou a representatividade da FPC e a legitimidade da instituição alegando que se tratava de uma organização cuja ligação com a comunidade de praticantes era ínfima. Contestava-se, ainda, a forma como IPDJ estava a aplicar o programa nacional, em particular no caso da capoeira, pois desprezava o papel dos mestres, dos grupos de capoeira e todo um sistema de certificação de saberes forjado na informalidade e na proximidade com o mestre e com a aprendizagem da capoeira que não era meramente física, passando pela música e o conhecimento histórico da capoeira. Como tal, ela não era simplesmente mais um desporto de combate.

A réplica dada pelo responsável da reunião dava a saber que a capoeira não poderia dispor de exceções, devendo adequar-se à legislação do país como qualquer outra modalidade. As características peculiares da capoeira, segundo o técnico do IPDJ, poderiam também ser encontradas em outros desportos de combate e como tal deveriam ter o mesmo tratamento. Segundo o técnico do IPDJ:

\begin{abstract}
A razão manifestada pelo IPDJ para desenvolvimento de trabalho conjunto com a FPC foi de que a FPC terá sido a única entidade que manifestou preocupação e vontade em desenvolver trabalho sobre este processo de regulamentação da Capoeira junto do $I P D J$, visando o enquadramento de todos os profissionais que atuam e representam a Capoeira (Depoimento do técnico do IPDJ, 2014).
\end{abstract}

Mesmo tendo sido contestada a legitimidade da FPC, a posição por parte do IPDJ era de ater-se aos procedimentos legais, desconsiderando o fato de a FPC ser tida por todos por ilegítima e 
pouco representativa. Por fim, o referido técnico vaticinou de forma incisiva:

Todos aqueles que lecionam aulas de Capoeira tem que cumprir o que a lei prezê. Por conseguinte, para o IPDJ, todos aqueles que lecionam Capoeira (Mestres, Contra-Mestres, Professores, e outras designações de agente de ensino) são entendidos como Treinadores para o IPDJ (Depoimento do técnico do IPDJ, 2014).

Para a grande maioria dos capoeiristas, a capoeira é um saber popular ancorado em fortes tradições de origem africana. Alguns dos mestres presentes na reunião eram de uma geração de praticantes que chegou em Portugal durante os anos oitenta, depois de uma longa jornada de inserção na capoeira e em busca de difundi-la fora do Brasil. Os depoimentos que colhi apontavam para um grande sentimento de desprezo por parte do Estado português para com os profissionais que tinham, ao longo da sua vida, se dedicado tanto a ensinar esta arte afrodescendente fora do Brasil. A sua condição de mestres, adquirida em processos dolorosos de ensino e aprendizagem ao longo dos anos, teria sido reduzida ao papel de meros treinadores.

A partir de iniciativas criadas nas redes sociais, deu-se início um processo, ainda em curso, de embate que culminaria em dezembro de 2014 com a criação de uma nova federação a FNCP (Federação Nacional de Capoeira de Portugal), promovida por grupos locais para fazer frente à FPC. Alguns espaços virtuais protagonizaram o debate sobre este processo como o Mural da Capoeira em Portugal, página do facebook vocacionada para assuntos relacionados à capoeira em Portugal e o Portal Capoeira (2015), página da internet direcionada à divulgação da capoeira em geral. A partir destas fontes de divulgação foi realizado um cadastramento dos profissionais e divulgada uma petição para alterar a instituição que representa a capoeira junto ao IPDJ. 
O processo, entretanto, comporta várias contradições que se impõem pelas relações de poder entre os diferentes intervenientes. Contudo, apesar destas contradições, os fatos demonstram que ocorreram perdas e ganhos que reconfiguram as relações entre os intervenientes e relançam a capoeira em Portugal. Entre estas novas dinâmicas destacamos:

\section{A aproximação entre grupos de capoeira rivais QUe pouco TRAVAVAM CONTATO}

Durante o processo realizaram-se inúmeras reuniões que agregaram praticantes de todos os grupos e locais de Portugal. Estas reuniões proporcionaram o encontro de vários profissionais e grupos que possuíam "diferenças" entre si, mas que foram obrigados a criar espaços de diálogo e até resolver antigas querelas resultantes das rodas de capoeira, bem como da ocupação de espaços de mercado local.

\section{MaIOR ORganização dos GRUPOS TENDO EM CONTA NOVOS OBJETIVOS}

Muitos grupos em Portugal estão organizados em associações formais. Contudo, os que ainda não o tinham feito foram obrigados a registrarem os seus respectivos grupos de forma a incluírem-se no processo. Para tal, era preciso contatar outros grupos formalizados em associações e perceber as burocracias inerentes ao processo. Foram ainda debatidas novas formas de organização dos grupos, como a existência dos conselhos de mestres e realizaram-se debates sobre a democracia interna dos grupos, usualmente ancorados em hierarquizações rígidas. 


\section{A percepção de como lidar com o Estado e o seu Aparato BUROCRÁTICO}

Durante muito tempo as situações de informalidade imperaram na capoeira, nas relações institucionais, nos acordos entre parceiros para novos locais de treino, nos acertos salariais para aulas e performances. No entanto, o processo em questão veio lançar a necessidade de mediar as relações entre alunos e professores, bem como os grupos e as instituições a partir de currículos, papeladas, projetos e outros documentos.

\section{O REDIMENSIONAMENTO DO DEBATE SOBRE A}

LEGITIMIDADE ENTRE OS CAPOEIRISTAS

A necessidade de organização obrigou a que os praticantes tivessem de rever as suas posições sobre os colegas de trabalhos. Com a saída de muitos mestres brasileiros, líderes de grupos, de retorno ao Brasil ou para outras partes da Europa, muitos jovens portugueses foram obrigados a liderar os seus grupos. Muitas questões sobre as competências desses jovens foram levantadas bem como os percursos por eles traçados até a sua posição de liderança. A ideia de legitimidade teve de ser renegociada entre eles de forma a se reposicionarem nas suas relações de grupo bem como junto ao mercado da capoeira.

\section{O PAPEL DO BRASIL E DA CAPOEIRA ENQUANTO PATRIMÔNIO IMATERIAL}

Em novembro de 2014, a capoeira foi reconhecida pela UNESCO como património imaterial da humanidade em cerimônia realizada em Paris. A ocasião foi celebrada pelos capoeiristas em todo mundo e marcou um momento especial da história da capoeira no seu momento de expansão global. Longe de representar políticas públicas concretas em favor da capoeira, o reconhecimento significou um momento de reflexão e uma motivação extra para reabilitar a 
prática e abrir novos caminhos. Em Portugal, o fato ocorreu num momento em que se desenrolava o processo em causa neste artigo e foi motivo de reflexão entre os praticantes. Introduzo o fato de que, neste processo, os grupos de praticantes também entraram em contato com o consulado, a embaixada do Brasil e o Conselho de Cidadãos brasileiros em Lisboa a fim de que o governo brasileiro se posicionasse frente a estes assuntos.

\section{O REFORÇO DA IDENTIDADE EMIGRANTE}

Portugal historicamente possui uma vasta comunidade de emigrantes brasileiros que, nos últimos anos por conta da crise econômica, regressou ao Brasil ou encaminhou-se para outras partes da Europa. Muitos o fazem em situação de desconforto, uma vez que passaram longos períodos da sua vida longe do Brasil. O processo em questão veio a reforçar os laços entre os brasileiros capoeiristas, ainda residentes, e a necessidade de reinventar a sua comunidade emigrante, para além das fronteiras da prática da capoeira, inserindo-se de forma mais incisiva na sociedade portuguesa.

\section{A renegociaçÃo SEMÂNTICA dA CAPOEIra ENTRE O ESPORTE E A CULTURA}

Apesar da grande turbulência gerada entre a comunidade de praticantes, o processo finalizou-se em 2015 com a realização de formações promovidas por alguns grupos e centros privados de formação. Todo o processo foi coordenado e gerido pela Federação Portuguesa de Capoeira que forneceu os referenciais teóricos para a formação, bem como a sua certificação final. Grande parte dessas referências enquadrava a capoeira no campo esportivo, e os finalistas dos cursos saíram certificados como treinadores. Contudo, alguns grupos acabaram por subverter o conteúdo dos cursos, debatendo questões culturais inerentes à capoeira, sua relação com uma cultura 
afrodescendente, e reforçando esse aspecto, em detrimento do que pretendia o curso.

\section{Conclusão}

Os processos pensados por Elias (1992) como modernizadores e civilizacionais, que marcaram rupturas sociais profundas, continuam em curso. A globalização, como fenômeno da contemporaneidade, tem atuado fortemente nas revisões de modelos sociais considerados anacrônicos e ultrapassados, desprezando valores, construções e idiossincrasias. Apesar do reconhecimento internacional em torno da capoeira e do seu inconteste valor cultural, este fenômeno global padece ainda de formas de regulamentação que permitam valorizar os protagonistas da sua difusão, bem como aspectos basilares que constituem a capoeira.

Para os praticantes, a capoeira possui uma definição polissêmica que permite compreendê-la de várias formas, sendo uma luta, um desporto, uma dança, um jogo que possui uma ritualidade própria e que abraça essas designações, assim como muitas outras. Neste sentido, defini-la passa por conceituar o que ela não é. No entanto, fica claro que para o Estado, pouco importa este exercício exploratório do sentido da capoeira, muito menos que ela possa ser uma prática cultural ancorada em uma ancestralidade, um passado, uma memória e um saber, cuja passagem faz-se por via da vivência e da prática. O que lhes interessa é aplicar a lei e ordenar o que não está na "prateleira correta". Para as sociedades ocidentais onde a capoeira se instalou, o procedimento de rotulação e ordenamento é parte da liturgia habitual da própria construção social cotidiana. Contudo, como foi possível constatar, também no Brasil esse jogo polissêmico da capoeira enquanto esporte ou cultura foi ensaiado ao longo do século $X X$ e as razões para assim proceder não diferem de outros locais: as tensões entre a tradição e modernização, as disputas 
de nichos mercadológicos e a inserção da capoeira no contexto do mercado capitalista global.

À parte destas questões, foi possível verificar que todo o processo comportou contradições que opuseram os capoeiristas e testaram as suas capacidades organizativas. No entanto, aspectos intrínsecos ao debate acabaram por possibilitar o reordenamento da comunidade de praticantes, aproximando grupos antes rivais, e uma reavaliação do sentido de legitimidade entre os diferentes setores.

Embora o debate sobre a lusofonia não tenha sido chamado à temática por parte do Estado, ator proeminente no processo de profissionalização e institucionalização da capoeira, ele esteve sempre subentendido como parte inerente ao debate pelos seus agentes diretos de fomento da capoeira, a saber: os portugueses, luso-africanos e brasileiros. Para eles, subjaz a ideia de que a capoeira é um bem cultural e que pertence a um universo mais vasto, forjada no âmbito do atlântico negro lusófono. Por Atlântico Negro, compreende-se a expressão cunhada por Paul Gilroy (2001) que abrange o conjunto das culturas, memórias e identidades formadas no processo de passagem do Atlântico pelos escravizados da África.

O processo demonstrou ainda a importância do Estado brasileiro na elaboração de políticas públicas que possam dar suporte aos brasileiros fora do Brasil que levam adiante um dos símbolos mais proeminentes de brasilidade. Como o processo ainda decorre, não sabemos o contorno do seu fim. Seja qual for o final do capítulo, certamente, poderemos ainda perguntar: a capoeira é cultura ou desporto?

\section{REFERÊNCIAS}

ASSUNÇÃO, Matthias Röhrig. Ringue ou academia? A emergência dos estilos modernos da capoeira no seu contexto global. História, Ciências, Saúde-Manguinhos, Rio de Janeiro, v. 21, n. 1, jan./mar. 2014. Disponível em: <http://www.scielo.br/ scielo.php?script=sci_arttext\&pid=S0104-59702014000100135>. Acesso em: $24 \mathrm{fev}$. 2015. 
BURLAMAQUI, Aníbal. Ginástica nacional (capoeiragem), metodizada e regrada. Rio de Janeiro, 1928.

ELIAS, Norbert. O processo civilizador: uma história dos costumes. Rio de Janeiro: J. Zahar, 1992.

FALCÃO, José Luis Cirqueira. A escolarização da capoeira. Brasília: Editora Royal Court, 1996.

FALCÃO, José Luis Cirqueira. O jogo da capoeira em jogo e a construção da práxis capoeirana. 2004. Tese (Doutorado em Educação) - Universidade Federal da Bahia, Salvador, 2004.

FEDERAÇÃO PORTUGUESA DE CAPOEIRA. Disponível em: <http://www. fpcapoeira.org/>. Acesso em: 24 fev. 2015.

FONSECA, Vivian. A capoeira e o mundo do trabalho: embates acerca da profissionalização. Cadernos AEL, Campinas, n. 28, 2010. Disponível em: <http:// www.ifch.unicamp.br/ojs/index.php/ael/article/view/2586/1996>. Acesso em: 1 abr. 2015.

GILROY, Paul. O atlântico negro: modernidade e dupla consciência. São Paulo: Editora 34, 2001.

NASCIMENTO, Ricardo César Carvalho. Mandinga for export: a globalização da capoeira na Europa. 2015. Tese (Doutorado) - Faculdade de Ciências Sociais e Humanas da Universidade Nova de Lisboa, Lisboa, 2015.

PORTAL CAPOEIRA. Disponível em: <http://portalcapoeira.com/>. Acesso em: 24 fev. 2015.

POURDEUS JUNIOR, Ismael. Portugal em transe: transnacionalização das religiões afro-brasileiras: conversão e performance. Lisboa: Imprensa das Ciências Sociais, 2009.

SARAIVA, Clara. Afro-brazilian religions in Portugal: bruxos, priests and pais de santo. Disponível em: <https://etnografica.revues.org/292>. Acesso em: 8 fev. 2011.

SOARES, Carlos Eugénio Líbano. A negrada instituição: os capoeiras no Rio de Janeiro. Rio de Janeiro: Prefeitura Municipal do Rio de Janeiro, 1994. (Coleção Biblioteca Carioca).

UNIÃO EUROPEIA. O desporto da UE. Disponível em: <https://europa.eu/ european-union/topics/sport_pt>. Acesso em: 12 dez. 2016.

VIANNA, Carlos. A comunidade brasileira em Portugal. Lisboa: Presidência da Casa do Brasil, 2002.

VIEIRA, Luís Renato. O jogo da capoeira: cultura popular no Brasil. Rio de Janeiro: Sprint, 1995. 